\title{
CLINICAL PROFILE OF ABDOMINAL TUBERCULOSIS IN A TERTIARY CARE CENTRE OF CENTRAL INDIA- A DESCRIPTIVE OBSERVATIONAL STUDY
}

\author{
Rishikant Vashistha1, Kiran Somani², Akhilesh Patel ${ }^{3},{ }^{1}$ Madhavi Maheshwari', Sanjay Datey ${ }^{5}$
}

${ }^{1}$ Associate Professor, Department of General Surgery, Sri Aurobindo Medical College and Postgraduate Institute, Indore, M. P., India.

2 Professor, Department of General Surgery, Sri Aurobindo Medical College and Postgraduate Institute, Indore, M. P., India.

${ }^{3}$ Resident, Department of General Surgery, Sri Aurobindo Medical College and Postgraduate Institute, Indore, M. P., India.

${ }^{4}$ Medical Officer, SAMC \& PGI, Indore, M. P., India.

5Professor, Department of General Surgery, Sri Aurobindo Medical College and Postgraduate Institute, Indore, M. P., India.

ABSTRACT

\section{BACKGROUND}

Tuberculosis of abdomen is an increasingly seen clinical problem. The disease can mimic many other intra-abdominal pathologies and becomes a diagnostic challenge to the treating physician. Abdominal tuberculosis can be associated with pulmonary tuberculosis or can be seen as an isolated pathology. With the advent of newer imaging modalities and investigations like ADA levels and CB-NAAT, the diagnosis can be reached with a reasonable accuracy.

The objective of the study was to evaluate the clinico-pathological profile of patients with abdominal tuberculosis in our institution.

\section{MATERIALS AND METHODS}

We have conducted this descriptive observational study for a period of one and a half years, i.e. from $1^{\text {st }}$ Jan 2017 to $30^{\text {th }}$ June 2018 . All the patients who were admitted and were diagnosed as cases of abdominal tuberculosis were included in this study. The collected data was tabulated and analysed statistically.

\section{RESULTS}

This descriptive observational study included forty patients of abdominal tuberculosis during a period of one and a half years. Distension of abdomen (80\%) with pain and anorexia (78\%) were the commonest presenting symptoms. Forty five percent patients were between 18 and 40 years of age. Lower socioeconomic strata patients were $72.5 \%$, which suggests that poor sanitation and lack of good nutrition are major factors in the causation of tuberculosis. Raised ADA levels (in 92.5\%) and po sitive CB-NAAT status (92.5\%) were significant values. Imaging modalities like ultrasonography and computerised tomography were useful in reaching the diagnosis in more than fifty percent of patients of abdominal tuberculosis.

\section{CONCLUSION}

Abdominal tuberculosis is a disease with varied presentations. It can mimic many other abdominal pathologies. Diagnosis of abdominal tuberculosis is sometimes difficult. Delay in the diagnosis can increase the morbidity and mortality of this condition. High index of suspicion on the part of the treating physician is of greatest value. Newer advents of imaging modalities and investigations like CB-NAAT, ADA levels etc. are helpful in making an early diagnosis. Tuberculosis being a communicable infection, should be prevented and eradicated by us to safeguard the future generations.

\section{KEY WORDS}

Abdominal Tuberculosis, Koch's Abdomen, Ileal Perforation.

HOW TO CITE THIS ARTICLE: Vashistha R, Somani K, Patel A, et al. Clinical profile of abdominal tuberculosis in a tertiary care centre of Central India- a descriptive observational study. J. Evolution Med. Dent. Sci. 2018;7(33):3699-3702, DOI: $10.14260 /$ jemds/2018/830

\section{BACKGROUND}

Koch's abdomen or the tuberculosis of abdominal viscera is an increasing clinical problem. Tubercular abdomen poses a great challenge to the treating physician, as it can mimic any other abdominal pathology. A high index of suspicion is needed for an early diagnosis. Delay in diagnosis is very common and it increases the number and gravity of the complications. Early diagnosis and prompt initiation of antitubercular treatment with appropriate surgical procedures as

'Financial or Other Competing Interest': None.

Submission 18-07-2018, Peer Review 31-07-2018,

Acceptance 02-08-2018, Published 13-08-2018.

Corresponding Author:

Dr. Kiran Somani,

\#205, Tirupati Apartment-6,

Gumasta Nagar, Indore-452009,

Madhya Pradesh, India.

E-mail: somanikiran@yahoo.com

DOI: $10.14260 /$ jemds $/ 2018 / 830$

\section{(c) (i) $(?$}

and when needed can reduce the morbidity and mortality. Abdomen is involved in $11 \%$ of patients with extrapulmonary tuberculosis. The most common site of involvement in order of descending frequency are the ascending colon, jejunum, appendix, duodenum, stomach, oesophagus, sigmoid colon and rectum.(1)

Tuberculosis is an age-old disease, which has affected the humans for many centuries. The earliest reference to intestinal tuberculosis can be traced to 1643 , when an autopsy had revealed ulcerative intestinal lesions and a pulmonary cavity in Louis XIII.(2) John Hunter described the tubercles on various abdominal organs like liver, spleen, uterus, colon and small intestines which were postulated to arise from the lungs. The tubercles on the small intestine were responsible causation of ulcers on the mucous membranes.(3) Advent of effective antitubercular drugs have changed the overall scenario of tuberculosis. Autopsy studies on patients with pulmonary tuberculosis revealed $50-55 \%$ intestinal involvement before the development of anti- 
tubercular drugs. Greater was the pulmonary involvement, more was the incidence of intestinal lesions.

Tuberculosis has become an emerging world health issue with growing number of immunocompromised patients, largely related to acquired immunodeficiency syndrome pandemic. The spread of the disease is accentuated by growing poverty, lack of basic sanitation, overcrowding and multidrug resistant strains. Incidence of abdominal tuberculosis is rising consistently with the overall incidence of pulmonary tuberculosis.

Clinical features of abdominal tuberculosis are characterised by deception. Earlier visits by patients with vague symptoms and absence of physical signs makes it a difficult diagnostic proposition. Abdominal tuberculosis can almost mimic any benign or malignant condition of the abdomen. Most of the occasions abdominal tuberculosis comes as an unexpected but welcomed diagnosis, while investigating suspected malignancy. It is welcomed because it is considered a lesser evil, as it is treatable by drugs most of the time. Newer laboratory and radiological methods have revolutionised the diagnostic armamentarium of clinicians, but still the clinical acumen and high index of suspicion plays a crucial role in the early diagnosis of abdominal tuberculosis.

This descriptive observational study was conducted in Sri Aurobindo Medical College and Postgraduate Institute of Indore, MP which is a leading tertiary care centre of Central India. The centre is getting referrals from all over the MP and adjoining parts of Gujarat, Rajasthan and Maharashtra. Koch's abdomen, although a treatable disease, but incapacitates the sufferer and his family physically and financially. If the bread winner of the family is the sufferer then repeated hospital admissions, prolonged treatment and financial constraints due to his absenteeism from work affects the whole family severely. We have analysed the demographic data, clinical presentation, comorbid conditions and the outcome of patients of Koch's abdomen in this study.

\section{Review of Literature}

We have reviewed the available literature on Abdominal Tuberculosis in detail and we came to know that most of the studies are published from India. Abdominal tuberculosis continues to be a major health problem in the developing and underdeveloped countries. Autopsy studies will be of great value in finding the incidence in the population at large as many subclinical cases are not diagnosed. Pimparkar had done autopsies on 11,746 in K.E.M. Hospital, Mumbai and found evidence of abdominal tuberculosis in 3.72\%.(4) With the introduction of drugs, the incidence of pulmonary tuberculosis is reducing and along with it the abdominal tuberculosis is showing a downward trend. Rathi et al have found that HIV positivity is higher in abdominal tuberculosis (16.6\%) as compared to pulmonary tuberculosis (6.9\%).(5) This finding suggests that with increasing number of HIV seropositive cases, we should expect a rise in the number of abdominal tuberculosis patients.

Abdominal tuberculosis is probably due to reactivation of a dormant focus. From the primary pulmonary lesion in childhood, infection comes to the gastrointestinal tract by haematogenous route and remains dormant. It may also be caused by swallowed bacilli, which get entangled in Peyer's patches. From the Peyer's patches they go to the mesenteric lymph nodes, where they remain dormant.(6) The most common site of involvement is the ileocaecal region, possibly because of increased physiological stasis and abundance of lymphoid tissue at this site.(7) Abdominal tuberculosis involves the gastrointestinal tract, peritoneum, lymph nodes and solid viscera e.g. liver, spleen, pancreas, etc. The ileum and caecum are most commonly involved and are affected in three-fourths of the cases. Other sites of involvement are the ascending colon, jejunum, appendix, duodenum, stomach, oesophagus, sigmoid colon and rectum in that order of frequency. Multiple areas can be affected simultaneously. ${ }^{(8)}$ Three types of intestinal lesions are seen commonlyulcerative, stricturous and hypertrophic. Strictures are because of cicatricial healing of ulcers. They can be further aggravated by occlusive vascular changes in the mesenteric vessels. Colonic lesions are ulcerative and hypertrophic and are usually associated with ileocaecal tuberculosis of hypertrophic type. Peritoneal involvement is very common and can be associated in females with tubal pathologies. Two types of peritoneal involvement, i.e. ascetic or adhesive are seen. Lymph nodes in the mesentery and retroperitoneum can enlarge, caseate and later can get calcified. Disseminated abdominal tuberculosis can also be seen with extensive involvement of peritoneum, mesenteric nodes, intestine and solid organs, particularly in the immunocompromised patients.(9) Clinical presentation of Koch's abdomen depends on the organ affected. Acute presentations are due to perforated ulcers and adhesive/ strictures and intestinal obstructions. These are preceded by vague abdominal symptoms of bloating, irregularity of bowel habit, loss of weight etc. in the past history. Other symptoms are diarrhoea of malabsorption, lump in abdomen with colicky pain due to stricture causing obstruction and occult blood in stools. The most common symptoms are abdominal pain with loss of weight. Main results of studies done on abdominal tuberculosis have been depicted in the following table.

\begin{tabular}{|c|c|c|c|}
\hline Symptom & $\begin{array}{c}\text { Mukewar } \\
\text { et al }\end{array}$ & $\begin{array}{c}\text { Makharia } \\
\text { et al }\end{array}$ & $\begin{array}{c}\text { Khan } \\
\text { et al }\end{array}$ \\
\hline Abdominal pain & $80.6 \%$ & $90.5 \%$ & $93 \%$ \\
\hline Weight loss & $74.6 \%$ & $83 \%$ & $47 \%$ \\
\hline Loss of appetite & $62.7 \%$ & $69.8 \%$ & $52 \%$ \\
\hline Fever & $40.30 \%$ & $41.5 \%$ & $64 \%$ \\
\hline Diarrhoea & $16.4 \%$ & $37.7 \%$ & $12 \%$ \\
\hline Constipation & $25 \%$ & $49 \%$ & $31 \%$ \\
\hline Bleeding per rectum & $11.9 \%$ & $16.9 \%$ & $14 \%$ \\
\hline Table 1. Symptoms of Abdominal Tuberculosis (Three \\
Series Compiled)(10,11,12) \\
\hline
\end{tabular}

Clinical picture of abdominal tuberculosis is not clear all the times. It can mimic any other abdominal pathology. Routine investigations also are equivocal and apart from showing mild anaemia and raised erythrocyte sedimentation rate in 50 to 80 percent of cases. Ultrasound examination may reveal some useful findings, which could help in making a provisional diagnosis of abdominal tuberculosis.(13) Presence of free fluid in cavity with septations or an interloop ascites is one preliminary finding on ultrasonography. Enlarged paraaortic or mesenteric nodes with evidence of central caseation or older nodes with calcification are also informative, as such findings are not seen in any malignancy. Bowel wall thickening, more so in the ileocaecal region with pulling up of caecum is a diagnostic finding of abdominal tuberculosis on ultrasonography. 
Computerised Tomography (CT) is the most helpful modality to assess intraluminal and extraluminal pathology and disease extent. The most common CT finding is concentric mural thickening of the ileocaecal region with or without proximal intestinal dilatation. Capsule endoscopy can be of great value in demonstration of intraluminal lesions and obtaining tissue diagnosis. Crohn's disease and abdominal tuberculosis have similar clinical picture and radiological features. Colonoscopic findings are helpful in the differential diagnosis of the two conditions. ADA levels of 30 units/L or above in the ascetic fluid are diagnostic.(14) GeneXpert assay has a high sensitivity (81\%) and specificity (99\%) in the extrapulmonary tuberculosis in studies from India (547 patients) and Europe (1068 patients).(15,16) Laparoscopy is a valuable tool, as it provides visual impression with histological evidence of peritoneal tuberculosis in an early stage of the disease. Laparoscopic findings of thickened peritoneum, presence of tubercles and adhesions are the classical diagnostic features of abdominal tuberculosis.

\section{MATERIALS AND METHODS}

This descriptive observational study was carried out over a period of one and a half years, i.e. from $1^{\text {st }}$ January 2017 to $30^{\text {th }}$ June 2018. Study commenced after approval of the subject by the Institutional Ethics and Research Committee. All patients who were admitted with evidence of abdominal tuberculosis were included in the study. Acute abdominal conditions which required an exploratory laparotomy, which revealed features of abdominal tuberculosis were included. Patients with chronic abdominal complaints were investigated and those with histological or serological evidence of tuberculosis were included. As our hospital is getting referrals from surrounding states, many patients were admitted with a confirmed diagnosis of abdominal tuberculosis. After taking the consent for inclusion in the study, patients were included in the study. Demographic data pertaining to the subject was recorded. Detailed history was taken and thorough clinical examination was done. All patients were investigated for haematological and biochemical abnormalities. Serological tests were done and further plan was decided. Most of the patients in our study have undergone either a laparotomy or a diagnostic laparoscopy, so we could get a tissue diagnosis. The collected data was entered in a Master Chart and analysed by simple statistical methods of averages and percentages. At any stage of this study, the individual patient's identity was not disclosed.

\section{RESULTS}

This descriptive observational study on the clinical profile and outcome of abdominal tuberculosis was conducted from $1^{\text {st }}$ January 2017 to $30^{\text {th }}$ June 2018 for a period of one year and six months. The study included 40 patients of abdominal tuberculosis. Results of the study are as follows-

\begin{tabular}{|c|c|c|}
\hline Symptom & Number of Patients (n= 40) & $\mathbf{( \% )}$ \\
\hline Pain & 31 & 77.5 \\
\hline Distension & 33 & 82.5 \\
\hline Anorexia & 31 & 77.5 \\
\hline Constipation & 20 & 50 \\
\hline Diarrhoea & 04 & 10 \\
\hline Vomiting & 03 & 7.5 \\
\hline
\end{tabular}

Table 1. Shows the common symptoms in the patients. Abdominal pain, Anorexia with Distension were the

\begin{tabular}{|c|c|c|}
\hline \multicolumn{3}{|c|}{$\begin{array}{c}\text { commonest symptoms. Half of the patients (20/40) } \\
\text { complained of Constipation }\end{array}$} \\
\hline Symptom & Number of Patients (n= 40) & $\mathbf{( \% )}$ \\
\hline $\begin{array}{c}\text { Evening rise of } \\
\text { temperature }\end{array}$ & 34 & 85 \\
\hline Cough & 7 & 18 \\
\hline Weight loss & 34 & 85 \\
\hline Weakness & 36 & 90 \\
\hline \multicolumn{2}{|r|}{ Table 2. Constitutional Symptoms } \\
\hline
\end{tabular}

Table no. 2 shows that most of the patients had weight loss, weakness and evening rise of temperature as constitutional symptoms.

\begin{tabular}{|c|c|c|}
\hline Age Groups & Number of Patients (n= 40) & (\%) \\
\hline 18 to 30 years & 18 & 45 \\
\hline 31 to 40 years & 09 & 22.5 \\
\hline 41 to 50 years & 06 & 15 \\
\hline 51 to 60 years & 06 & 15 \\
\hline Above 60 years & 01 & 2.5 \\
\hline Table 3. Distribution of Abdominal Tuberculosis patients \\
according to Age Groups \\
\hline
\end{tabular}

More than half of the patients studied were from the third and fourth decade of life. We had 22 females vs. 18 male sufferers.

\begin{tabular}{|c|c|c|}
\hline Sex & Number & Percentage (\%) \\
\hline Male & 18 & 45 \\
\hline Female & 22 & 55 \\
\hline \multicolumn{3}{|c|}{ Table 4. Sex Distribution } \\
\hline
\end{tabular}

\begin{tabular}{|c|c|c|}
\hline Indian Rupees Per Month & Number of Cases & (\%) \\
\hline Lower class (<4000) & 29 & $72.5 \%$ \\
\hline Middle class (4000 to 20000) & 09 & $22.5 \%$ \\
\hline Higher class (> 20000) & 02 & $5 \%$ \\
\hline \multicolumn{2}{|c|}{ Table 5. Socioeconomic Status } \\
\hline
\end{tabular}

\begin{tabular}{|c|c|c|}
\hline Distribution & Number (n= 40) & Percentage (\%) \\
\hline Rural & 23 & $57.5 \%$ \\
\hline Urban & 17 & $42.5 \%$ \\
\hline \multicolumn{2}{|r|}{ Table 6. Urban/Rural Distribution } \\
\hline \multicolumn{2}{|r}{}
\end{tabular}

\begin{tabular}{|c|c|c|}
\hline Serum ADA Level & Number of Cases (n= 40) & (\%) \\
\hline Raised & 37 & $92.5 \%$ \\
\hline Within normal limit & 03 & $7.5 \%$ \\
\hline \multicolumn{2}{|c|}{ Table 7. Changes of Serum ADA in cases of Abdominal } \\
Tuberculosis \\
\hline
\end{tabular}

\begin{tabular}{|c|c|c|}
\hline CB-NAAT & $\begin{array}{c}\text { Number of Cases of } \\
\text { Abdominal Tuberculosis }\end{array}$ & (\%) \\
\hline Positive & 37 & $92.5 \%$ \\
\hline Negative & 03 & $7.5 \%$ \\
\hline \multicolumn{2}{|c|}{ Table 8. Changes of CB-NAAT in cases of Abdominal } \\
Tuberculosis
\end{tabular}

\begin{tabular}{|c|c|c|}
\hline Findings & Number of Cases & Percentage (\%) \\
\hline Positive & 36 & $90 \%$ \\
\hline Negative & 04 & $10 \%$ \\
\hline \multicolumn{2}{|c|}{ Table 9. Computerised Tomographic Findings } \\
\hline
\end{tabular}




\begin{tabular}{|c|c|c|}
\hline CT Finding & Number of Cases (n= 36) & (\%) \\
\hline $\begin{array}{c}\text { Para-aortic and } \\
\text { Mesenteric node } \\
\text { enlargement with } \\
\text { central necrosis }\end{array}$ & 12 & 33.0 \\
\hline $\begin{array}{c}\text { Ascites with } \\
\text { lymphadenopathy }\end{array}$ & 19 & 52.7 \\
\hline Tubo-ovarian mass & 02 & 5.5 \\
\hline $\begin{array}{c}\text { Bowel loops } \\
\text { cocooning with } \\
\text { ascites }\end{array}$ & 02 & 5.5 \\
\hline Calcified lymph node & 01 & 2.7 \\
\hline \multicolumn{2}{|c|}{ Table 10. Common CT Findings } \\
\hline
\end{tabular}

suspicion on the part of the treating physician is of greatest value. Newer advents of imaging modalities and investigations like CB-NAAT, ADA levels etc. are helpful in making an early diagnosis. Tuberculosis being a communicable infection should be prevented and eradicated by us to safeguard the future generations. Abdominal tuberculosis is common in our country and larger studies on the topic can be helpful in evaluation of diagnostic methods and treatment modalities.

\section{REFERENCES}

[1] Rathi P, Gambhire P. Abdominal tuberculosis. Journal of Association of Physicians of India 2016;64(2):3847.

\begin{tabular}{|c|c|c|}
\hline Comorbidity & Number (n= 40) & Percentage (\%) \\
\hline Diabetes Mellitus & 03 & $7.5 \%$ \\
\hline Hypertension & 03 & $7.5 \%$ \\
\hline Hyperthyroidism & 02 & $5 \%$ \\
\hline Typhoid fever & 02 & $5 \%$ \\
\hline HIV & 01 & $2.5 \%$ \\
\hline HbsAg & 01 & 2.55 \\
\hline \multicolumn{2}{|c|}{ Table 11. Co-morbid conditions seen in cases of } \\
Abdominal Tuberculosis \\
\hline
\end{tabular}

[2] Paustian FF. Tuberculosis of the intestine. In: Bockus H, edr. Gastroenterology. Saunders 1976: p. 750-74.

[3] Hunter J. From works of John Hunter. Lectures on surgery. Vol. 1. 1835: p. 567.

[4] Pimparkar BD. Abdominal tuberculosis. J Assoc Physicians India 1977;25(11):801-11.

[5] Rathi PM, Amrapurkar DN, Parikh SS, et al. Impact of human immunodeficiency virus infection on abdominal tuberculosis in western India. J Clin Gastroenteol 1997;24(1):43-8.

\section{DISCUSSION}

Abdominal tuberculosis is a common cause of chronic abdominal pain and related morbidity and mortality. Many patients remain sick for longer durations and remain absent from their workplace. Absenteeism sometimes leads to loss of jobs and financial setbacks resulting in disturbed family. Young female sufferers of abdominal tuberculosis get genital tract involvement resulting in infertility in addition to problems in the gastrointestinal tract. Social stigma of infertility caused by abdominal tuberculosis hurts mentally to the patient. In our study, the commonest symptom in the patients $(82.5 \%)$ was distension of abdomen with anorexia and pain. This could be because of multiple strictures or adhesions. Eighty five percent patients also complained of weight loss and evening rise of temperature. Sex ratio (1: 1) for of the sufferers in our study was equal for male-female patients. More than fifty percent patients belonged to the age group between 20 and 40 years. These are the productive years of one's life and prolonged morbidity in this period of life could be detrimental. Seventy two percent patients belonged to the lower socioeconomic strata of the society, which again substantiates the age-old dictum that tuberculosis is the disease of poor. Environmental factors like poor sanitation, crowded houses and poor nutrition plays an important role in causation of the disease. Serum ADA levels and CB-NAAT definitely are very sensitive and specific indicators of extrapulmonary tuberculosis, which has been corroborated in this study. Radiological investigations (USG and CT) have proved to be valuable assets in the diagnosis of abdominal tuberculosis. Early diagnosis and prompt treatment are crucial in reducing the morbidity and thereby the mortality of abdominal tuberculosis.

\section{CONCLUSION}

Abdominal tuberculosis is a disease with varied presentations. It can mimic many other abdominal pathologies. Diagnosis of abdominal tuberculosis is sometimes difficult. Delay in the diagnosis can increase the morbidity and mortality of this condition. High index of

[6] Vij JC, Malhotra V, Choudhary V, et al. A clinicopathological study of abdominal tuberculosis. Indian J of Tuberculosis 1992;39(4):213-20.

[7] Sharp JF, Goldman M. Abdominal tuberculosis in East Birmingham: a 16 year study. Postgrad Med J 1987;63(741):539-42.

[8] Bhansali SK. Abdominal tuberculosis. Experience with 300 cases. Am J Gastroenterol 1977;67(4):324-37.

[9] Prakash A. Ulcero-constrictive tuberculosis of the bowel. Int Surg 1978;63(5):23-9.

[10] Mukewar S, Mukewar S, Ravi R, et al. Colon tuberculosis: endoscopic features and prospective endoscopic follow up after anti-tubercular treatment. Clinical and Translational Gastroenterology 2012;3:e24.

[11] Makharia GK, Shrivastav S, Das P, et al. Clinical, endoscopic and histological differentiation between Crohn's disease and abdominal tuberculosis. Am J Gastroenterol 2010;105(3):642-51.

[12] Khan R, Abid S, Jafri W, et al. Diagnostic dilemma of abdominal tuberculosis in non-HIV patients: an ongoing challenge for physicians. World J Gastroenterol 2006;12(39):6371-5.

[13] Kedar RP, Shah PP, Shivde RS, et al. Sonographic findings in gastrointestinal and peritoneal tuberculosis. Clin Radiol 1994;49(1):24-9.

[14] Gupta VK, Mukherjee S, Dutta SK, et al. Diagnostic evaluation of ascetic adenosine deaminase activity in tuberculous peritonitis. J Assoc Physicians India 1992;40:387-9.

[15] Vadwai V, Boehme C, Nabeta P, et al. Xpert MTB/RIF: a new pillar in the diagnosis of extrapulmonary tuberculosis? J Clin Microbiol 2011;49(7):2540-5.

[16] Tortolli E, Russo C, Piersimoni C, et al. Clinical validation of Xpert MTB/RIF for the diagnosis of extrapulmonary tuberculosis. Eur Respir J 2012;40(2):442-7. 